\title{
Idiopathic Facial Paralysis (Bell’s palsy)
}

\author{
Bouguezzi Adel*, Souid Kawthar, Derbel Amine, Ben Youssef Souha, Boughzala Abdellatif \\ Department of medicine and oral surgery, University Hospital Farhat Hached, Sousse, Tunisia \\ *Corresponding author: dr-adel@live.fr
}

Received August 15, 2014; Revised September 01, 2014; Accepted September 18, 2014

\begin{abstract}
Bell's palsy is defined as a neuropathy of the peripheral seventh cranial nerve or the facial nerve. It is usually from an idiopathic cause but it can result from traumatic, compressive, infective, inflammatory or metabolic abnormalities involving the facial nerve. Bell's palsy is more common in adults than in children. We present a case of Bell's palsy in an 38-year-old women who completely recovered after treatment with oral antiviral agents and steroids followed by regular facial physiotherapy. The dilemma in management of Bell's palsy with a review of relevant literature is discussed in this report.
\end{abstract}

Keywords: Bell's palsy, facial nerve, oral acyclovir, corticosteroids

Cite This Article: Bouguezzi Adel, Souid Kawthar, Derbel Amine, Ben Youssef Souha, and Boughzala Abdellatif, "Idiopathic Facial Paralysis (Bell's palsy)." International Journal of Dental Sciences and Research, vol. 2, no. 5A (2014): 1-4. doi: 10.12691/ijdsr-2-5A-1.

\section{Introduction}

Bell's palsy is named after Dr. Charles Bell, who, in 1821, described complete facial paralysis after injury of the stylomastoid foramen [1]. It can be defined as acute peripheral facial nerve palsy usually due to an unknown cause. It can result from traumatic, compressive, infective, inflammatory or metabolic abnormalities involving the facial nerve [2]. It is typically unilateral and can be complete or partial [3]. Affected patients are usually unable to close their eyes. Facial appearance becomes asymmetric, and saliva dribbles down the angle of the mouth. Depending on the site of the lesion, some patients may complain of noise intolerance or loss of taste sensation $[2,4]$.

Bell's palsy is more common in adults than in children. Although there is agreement on the definition, there is no consensus regarding the etiology, diagnostic approach or management of this enigmatic condition and role of steroids in treating patients with Bell's palsy is still under trial [4]. We present a case of Bell's palsy in a woman with a remarkable recovery following a short course of oral anti vial drugs and steroids. The management options and outcome are discussed with a review of relevant literature.

\section{Case Report}

An 38 year-old-woman presented to the department of dentistry (Unit of medicine and oral surgery) of the University Hospital Farhat Hached Sousse, Tunisia, with complaints of inability to completely close the left eye since three days associated with dribbling of food from the left side of mouth. The patient denies any history of excessive watering from the eyes, fever or recent upper respiratory tract infection. There was no history suggestive of taste disturbances, tingling sensation over face and weakness or numbness of the body.

An extraoral exam revealed left-sided facial nerve paralysis. The left muscles of facial expression did not participate when the patient smiled. No swelling was apparent. The left eye would close only partially Figure 1.

The patient had experienced no previous serious illnesses or injuries. There were no known drug allergies nor were medications being taken.

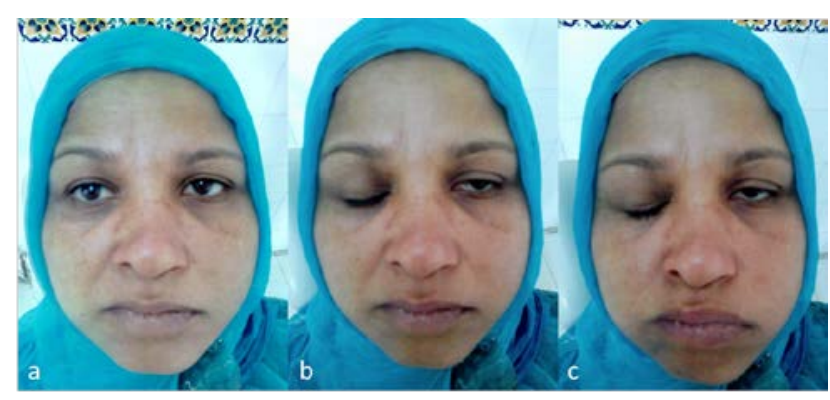

Figure 1. Facial aspect showing Bell's palsy on the left side

(a) No movement in the upper left eyebrow

(b) Incomplete left eye closure.

(c) Absence of movement in the left portion of the labial orbicular muscle.

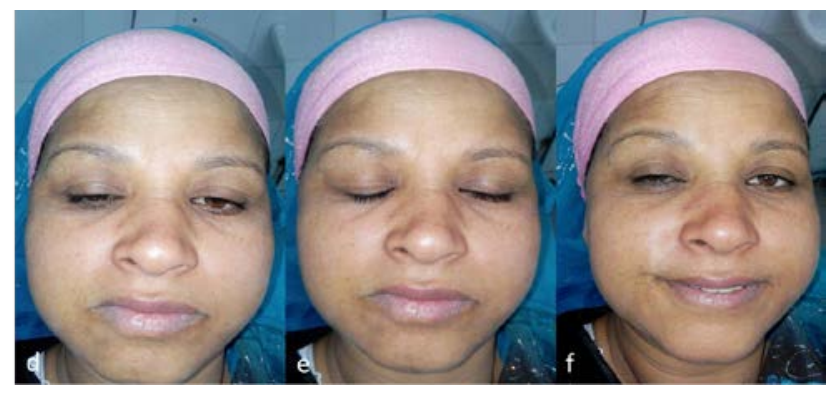

Figure 2. Facial aspect of patient after recovery of facial movement 
(d) Normal left eyebrow movement

(e) Complete closure of the left eye

(f) Normal, symmetric smile

Blood investigations included a normal hemoglobin level, total count, differential count and ESR. Pure tone audiometry confirmed absence of any hearing abnormality. An initial working diagnosis of Bell's palsy was made and the patient was educated about the disease process, therapeutic interventions and anticipated course of the disease. The conservative line of management with oral Acyclovir $400 \mathrm{mg}$ five times a day for a period of seven days and oral prednisolone $20 \mathrm{mg}$ three times a day for a period of ten days was administered. Adequate eye care was given by taping the eyes in the night during sleep and administration of sterile tear drops to prevent dryness of the eye. Facial physiotherapy was given for a period of 14 days.

The patient was reviewed over the next month and a remarkable recovery was noted Figure 2.

\section{Discussion}

Bell's palsy is defined as a neuropathy of the peripheral seventh cranial nerve or the facial nerve. It is usually from an idiopathic cause but it can result from traumatic, compressive, infective, inflammatory or metabolic abnormalities involving the facial nerve. The incidence of Bell's palsy is 20 to 30 cases per 100,000 people per year. [5], it accounts for 60 to 75 percent of all cases of unilateral facial paralysis. It is generally a unilateral disease affecting both sides of the face equally [4]. A child with an acute onset of unilateral facial weakness most likely has Bell's palsy, a careful history of the onset and progress of paralysis is important because gradual onset of more than two week's duration is strongly suggestive of a mass lesion. Medical history should include recent rashes, arthralgias, or fevers; history of peripheral nerve palsy; exposure to influenza vaccine or new medications; and exposure to ticks or areas where Lyme disease is endemic [7].

The physical examination includes careful inspection of the ear canal, tympanic membrane, and oropharynx, as well as evaluation of peripheral nerve functions in the extremities and palpation of the parotid gland. In order to assess forehead involvement, physical examination should also include evaluation of cranial nerve function, including all facial muscles. Laboratory testing is not usually indicated. However, because diabetes mellitus is present in more than 10 percent of patients with Bell's palsy, fasting glucose or A1C testing may be performed in patients with additional risk factors (e.g., family history, obesity, older than 30 years) [8]. Antibiotic therapy may be of benefit; therefore, Lyme antibody titers should be performed if the patient's history suggests possible exposure [7].

Bell's palsy rarely recurs. Recurrent or bilateral facial palsy should prompt consideration of myasthenia gravis or lesions at the base of the brain, where the facial nerve exits the pons; such types of palsy occur in lymphoma, sarcoidosis, and Lyme disease [9]. In rare cases, patients with inflammatory demyelinating polyneuropathy (the Guillain-Barré syndrome) present with bilateral facial palsy but relatively little weakness of the extremities. In immunocompetent people, the Ramsay Hunt syndrome is neither recurrent nor bilateral.

\subsection{Pathogenesis of Bell's Palsy}

It remains controversial. Acute inflammation and edema of the facial nerve are thought to lead to entrapment of the nerve in the bony canal (especially in the labyrinthine segment), which leads to compression and ischemia [10,11]. An inflammatory process surrounds the nerve fibers. Many viruses, such as HIV, Epstein-Barr virus and hepatitis $B$ virus have been suspected in initiating this inflammation [12]. Signs and symptoms atypical for Bell's palsy should prompt further evaluation. Patients with insidious onset or forehead sparing should undergo imaging of the temporal bone. Those with bilateral palsies or those who do not improve within the first two or three weeks after onset of symptoms should be referred to a neurologist [7].

\subsection{Medical Managment}

Regardless of the degree of facial palsy present, the eye needs to be evaluated and managed to avoid disastrous ocular-related consequences that will manifest if incomplete eye closure is present such as a corneal abrasion or exposure keratitis. Especially in paretic cases, expectant management may be an acceptable treatment modality if the patient is closely followed for spontaneous recovery.

Numerous studies have investigated the role of steroids in addressing Bell's palsy, typically with regimens such as prednisone $1 \mathrm{mg} / \mathrm{kg} / \mathrm{d}$ up to $70-80 \mathrm{mg}$. This is commonly tapered after 5-7 days, although treatment may be extended if no improvement is appreciated. Many investigations have cited benefit to steroids $[13,14]$ especially if they are implemented early in the course of the disease $[15,16]$. Shafshak echoed the importance of prompt intervention, recommending beginning prednisolone within 24 hours of paralysis [17].

Austin evaluated prednisone in a randomized, doubleblinded, placebo-controlled trial and concluded that there was improved recovery with the medication. A statistically insignificant trend for denervation prevention was also observed [18]. This study and two others were included in a meta-analysis of 27 prospective and 20 retrospective trials investigating the benefit of steroids. These three studies qualified for the meta-analysis inclusion criteria seeking prospective, controlled trials utilizing at least 400mg of prednisone started within seven days of paralysis and concluded that steroids improved complete recovery by $17 \%$. There was a generally positive benefit observed in the excluded trials with an acquisition of complete recovery ranging between 49-97\% using steroids and 23-64\% without [19] the latest Cochrane Review at the time of this manuscript concurs with this sentiment that steroids increase the frequency of complete recovery [20].

There are reports that contradict these findings [21,22], and a literature review of nine studies over a 45 year-span comparing steroids to placebo did not note a difference in rate of recovery or synkinesis. Although acknowledging that most of these investigations were underpowered and that there was a beneficial trend observed in some of the studies, the mild side effect profile and potentially positive 
therapeutic effect to steroids led to the conclusion that there was "probable" benefit with steroids [23].

Controversy arises with the use of steroids in the pediatric population with Bell's palsy as no benefit was observed in children [24]. A literature review of nine reports over a thirty year-period could not definitively support the role of steroids in this demographic. Only one of the studies specifically targeted children, and no statistical sub-analysis was conducted on this population in the other trials. Although some benefit was observed in four of the investigations, heterogeneity among them all precluded a meta-analysis or establishing a formal recommendation [25].

Antivirals were evaluated as an adjuvant therapy to steroids in a double-blind trial combining prednisone with either acyclovir or placebo initiated within three days of paralysis onset. The combination of prednisone and acyclovir resulted in less facial weakness on MST and a lower rate of unsatisfactory recovery [6]. As individual treatment modalities,however, prednisone was felt to be more beneficial than acyclovir, [26] and a subsequent literature review cited a paucity of studies to assert a definite therapeutic benefit but supported the notion of a "possible" benefit with adding acyclovir to prednisone given the generally well-tolerated side effect profile to antiviral medications [23]. Similar positive observations were encountered with valacyclovir $[27,28]$ and the latest Cochrane Review at the time of this manuscript concluded that antivirals were beneficial when added to steroids but not as a single treatment endeavor apart from steroids [29].

\begin{tabular}{|c|c|c|}
\hline MEDICATION & DOSAGE (ORAL) & DURATION \\
\hline \multicolumn{3}{|c|}{ Corticosteroid } \\
\hline Prednisone & $\begin{array}{l}\text { Adults: } 1 \mathrm{mg} / \mathrm{kg} \text { daily (max } 80 \mathrm{mg} \text { ) } \\
\text { Children: generally not recommended }\end{array}$ & 7-14 days \\
\hline \multicolumn{3}{|c|}{ Antivirals } \\
\hline Acyclovif & $\begin{array}{l}\text { Adults: } 400-800 \mathrm{mg} 5 \text { times dally with prednisone } \\
\text { Children }>2 \text { y: } 80 \mathrm{mg} / \mathrm{kg} / \text { day in } 4 \text { divided doses (3,200 mg max) }\end{array}$ & $\begin{array}{l}7 \text { days } \\
5 \text { days }\end{array}$ \\
\hline Famciclovir & $\begin{array}{l}\text { Adults: } 750 \mathrm{mg} 3 \text { times daily with prednisone } \\
\text { Children: safety not established }\end{array}$ & 7 days \\
\hline Valacyclovir & $\begin{array}{l}\text { Adults: } 1,000 \mathrm{mg} \text { twice daily with prednisone } \\
\text { Children >12 y: } 1 \text { g/day in } 3 \text { divided doses }\end{array}$ & $\begin{array}{l}7 \text { days } \\
7 \text { days }\end{array}$ \\
\hline
\end{tabular}

Prescription medication dosing [30]

\subsection{Surgical Decompression}

Some patients with Bell's palsy may be candidates for surgery. The facial nerve may be compressed (and its conduction blocked) at its narrowest point, the entrance to the meatal foramen, occupied by the labyrinthine segment and geniculate ganglion. Among 12 patients with facialnerve paralysis who underwent decompression surgery, bulbous swelling of the facial nerve was seen proximal to the geniculate ganglion in 11, and intraoperative evokedpotential electromyography performed in 3 documented conduction block proximal to the geniculate ganglion [31].

The role of surgical decompression in management remains controversial. In a prospective observational study of 31 patients with complete paralysis and 90 percent or more nerve degeneration as determined by electroneurography, 91 percent of those who underwent decompression had a good outcome (i.e., a grade 1 or 2 on the House-Brackmann scale) by the seventh month, as compared with 42 percent of those who were treated with glucocorticoids [32]. Other observational studies comparing outcomes at 6 to 36 months after prednisone treatment with outcomes after decompression [33] have not confirmed a benefit of surgery, however. Data from randomized trials are lacking to compare surgery with medical therapy, and available data are limited by small samples, possible bias in the selection of patients for surgery, the use of varying surgical approaches and systems to assess facial function, and a lack of blinding in studies assessing functional outcomes.

After decompression surgery, permanent unilateral deafness may occur, with estimates ranging from less than 1 percent to 15 percent of patients[32]. Because severe degeneration of the facial nerve is probably irreversible after 2 to 3 weeks, [31] decompression should not be performed 14 days or more after the onset of paralysis.

\subsection{Complications}

Patients with Bell's palsy may be unable to close the eye on the affected side, which can lead to irritation and corneal ulceration. The eye should be lubricated with artificial tears until the facial paralysis resolves. Permanent eyelid weakness may require tarsorrhaphy or implantation of gold weights in the upper lid.

Facial asymmetry and muscular contractures may require cosmetic surgical procedures or botulinum toxin (Botox) injections. In these cases, consultation with an ophthalmologist or cosmetic surgeon is needed [34,35].

\section{Conclusion}

Patients developing Bell's palsy should be seen by a neurologist, oto-rhini-laryngologist, and ophtalmomogist with the least possible latency after onset of the palsy. All patients in whom secondary facial nerve palsy is suspected a diagnostic work-up for the presence or absence of possible causes should be assessed if there is a causal relation between the palsy and the detected cause or not. Though a final decision on the optimal therapy of actuely developing Bell's palsy cannot be actually proposed, patients should be provided with all measures to avoid secondary affection of the eyes if the lid closure is insufficient or in case of impaired tearing. In case steroids are used in diabetic patients, serum glucose should be frequently followed [36].

\section{References}

[1] Phil TR, Bell C. On the nerves, giving an account of some experiments on their structure and functions which lead to a new arrangement of the system. Phil Trans Roy Soc Lond 1821; 111: 398-428.

[2] Steiner I, Mattan Y. Bell's palsy and herpes viruses: to acyclovir or not to (acyclo)vir?. J Neurol Sci. 1999; 170(1): 19-23.

[3] Adour KK, Byl FM, Hilsinger RL Jr, Kahn ZM, Sheldon MI. The true natureof Bell's palsy: analysis of 1,000 consecutive patients. Laryngoscope 1978; 88(5): 787-801.

[4] Singhi P, Jain V. Bell's palsy in children. Semin Pediatr Neurol 2003; 10(4): 289-97.

[5] Hauser WA, Karnes WE, Annis J, Kurland LT. Incidence and prognosis of Bell's palsy in the population of Rochester, Minnesota. Mayo Clin Proc 1971; 46: 258-264. 
[6] Adour KK, Ruboyianes JM, Von Doersten PG, et al. Bell's palsy treatment with acyclovir and prednisone compared with prednisone alone: a double blind, randomized controlled trial. Ann Otol Rhinol Laryngol 1996; 105: 371-378.

[7] Jeffrey D T, Nandini K. Bell's Palsy: Diagnosis and Management. Am Fam Physician 2007; 76: 997-1002, 1004.

[8] Adour K, Wingerd J, Doty HE. Prevalence of concurrent diabetes mellitus and idiopathic facial paralysis (Bell's palsy). Diabetes 1975; 24: 449-51.

[9] Keane JR. Bilateral seventh nerve palsy: analysis of 43 cases and review of the literature. Neurology 1994; 44: 1198-1202.

[10] Yanagihara N, Honda N, Hato N, Murakami S. Edematous swelling of the facial nerve in Bell's palsy. Acta Otolaryngol 2000; 120(5): 667-71.

[11] Ahmed A. When is facial paralysis Bell palsy? Current diagnosis and treatment. Cleve Clin J Med 2005; 72(5): 398-401, 405.

[12] Araujo MR, Azenha MR, Capelari MM, Marzola C. Management of Bell's Palsy: A Report of 2 Cases. Journal (Canadian Dental Association). 2008; 74(9): 823-827.

[13] Adour KK, Wingerd J, Bell DN, et al. Prednisone treatment for idiopathic facial paralysis (Bell’s palsy). N Engl J Med 1972; 287: 1268-1272.

[14] Katusic SK, Beard CM, Wiederholt WC, et al. Incidence, clinical features, and prognosis in.

[15] Brown JS. Bell's palsy: A 5 year review of 174 consecutive cases: An attempted double blind study. Laryngoscope 1982; 92:13691373.

[16] Williamson IG, Whelan TR. The clinical problem of Bell's palsy: Is treatment with steroids.

[17] Shafshak TS, Essa AY, Bakey FA. The possible contributing factors for the success of steroid therapy in Bell's palsy: A clinical and electrophysiological study. J Laryngol Otol 1994; 108:940943.

[18] Austin JR, Peskind SP, Austin SG, et al. Idiopathic facial nerve paralysis: a randomized double blind controlled study of placebo versus prednisone. Laryngoscope 1993; 103: 1326-1333.

[19] Ramsey MJ, Der Simonian R, Holter MR, et al. Corticosteroid treatment for idiopathic facial nerve paralysis: A meta-analysis. Laryngoscope 2000; 110(3 Pt 1): 335-341.

[20] Salinas RA, Alvarez G, Daly F, Ferreira J. Corticosteroids for Bell's palsy (idiopathic facial paralysis). Cochrane Database Syst Rev 2010; 17(3): CD001942.

[21] May M, Wette R, Hardin WB Jr, et al. The use of steroids in Bell's palsy: A prospective controlled study. Laryngoscope 1976; 86: 1111-1122
[22] Stankiewicz JA. A review of the published data on steroids and idiopathic facial paralysis. Otolaryngol Head Neck Surg 1987; 97: 481-486.

[23] Grogan PM, Gronseth GS. Practice parameter: Steroids, acyclovir, and surgery for Bell's palsy (an evidence-based review): Report of the Quality Standards Subcommittee of the American Academy of Neurology. Neurology 2001; 56: 830-836.

[24] Prescott CA. Idiopathic facial nerve palsy in children and the effect of treatment with steroids. Int J Pediatr Otorhinolaryngol 1987; 13: 257-264.

[25] Salman MS, MacGregor DL. Should children with Bell's palsy be treated with corticosteroids? A systematic review. J Child Neurol 2001; 16: 565-568.

[26] De Diego J I, Prim MP, De Sarriá MJ, et al. Idiopathic facial paralysis: A randomized, prospective, and controlled study using single-dose prednisone versus acyclovir three times daily. Laryngoscope 1998; 108(4 Pt 1): 573-575.

[27] Axelsson S, Lindberg S, Stjernquist-Desatnik A. Outcome of treatment with valacyclovir and prednisone in patients with Bell's palsy. Ann Otol Rhinol Laryngol 2003; 112: 197-201.

[28] Hato N, Yamada H, Kohno $\mathrm{H}$, et al. Valacyclovir and prednisolone treatment for Bell's palsy: a multicenter, randomized, placebo-controlled study. Otol Neurotol 2007; 28(3): 408-413.

[29] Lockhart P, Daly F, Pitkethly M, et al. Antiviral treatment for Bell's palsy (idiopathic facial paralysis). Cochrane Database Syst Rev 2009; 7(4): CD001869.

[30] Clinical Pharmacology [online database]. Tampa, FL: Gold Standard, Inc; 2010. www.clinicalpharmacology.com.

[31] Fisch U, Esslen E. Total intratemporal exposure of the facial nerve: pathologic findings in Bell's palsy. Arch Otolaryngol 1972;95: 335-41.

[32] Gantz BJ, Rubinstein JT, Gidley P, Wood worth GG. Surgical management of Bell's palsy. Laryngoscope 1999; 109: 1177-88.

[33] May M, Klein SR, Taylor FH. Idiopathic (Bell's) facial palsy: natural history defies steroid or surgical treatment. Laryngoscope 1985; 95: 406-9.

[34] Bulstrode NW, Harrison DH. The phenomenon of the late recovered Bell's palsy: treatment options to improve facial symmetry. Plast Reconstr Surg. 2005; 115: 1466-1471.

[35] Holland NJ, Weiner GM. Recent developments in Bell's palsy. BMJ 2004; 329: 553-7.

[36] Sullivan FM, Swan IR, Donnan PT Early treatmentwith prednisolone or acyclovir in Bell's palsy. N Engl J Med 2007, 357: 1598-1607. 